\title{
PROCESS DEVELOPMENT, OPTIMIZATION AND VALIDATION OF MANUFACTURING PROCESS OF ALLOPURINOL
}

\author{
SAYYED MOHSINA CHISHTI*, NIMITA MANOCHA
}

Swami Vivekanand College of Pharmacy, Indore (M. P.)

"Email: sayyedmohsina001@gmail.com

Received: 08 Nov 2020, Revised and Accepted: 10 Jan 2021

\begin{abstract}
Objective: The objective of the present research work is to identify the critical parameters in the process that affect the quality of the finished product. The processs validation of the manufacturing process for Allopurinol tablet USP, 300 mg to be manufactured with change in manufacturing site and with increased batch size.

Methods: Prior to Scaling up to production, pilot batches were manufactured. Three consecutive commercial batches are to be produced using similar test equipment and in full compliance with cGMP and existing SOPs. Critical process parameters of the machine was set within operating range and was not exceeded upper and lower control limits during process operation. Equipment were operated within its assigned control limits, which shows upon scale up into new site, the specification for hardness did not meet requirements that had been set during development. There was no significant effect observed on thickness, friability, disintegration, dissolution, uniformity of dosage and were found within specification. Pre process batch was challenged by manufacturing product at upper and lower processing limits and circumstances which pose the greatest chance of process or product failure compared to ideal condition.
\end{abstract}

Results: Based on the data obtained from pre-process validation batch, operating ranges for compression force and machine speed had been established. Collected data shows robustness around these parameters and there is increased confidence that the process can be successfully scaled up under target conditions for these parameters.

Conclusion: From this study, it was concluded that process was optimized and gave a reproducible product that meet predetermined quality requirements and do so consistently and reliably.

Keywords: Allopurinol, Specification, Validation, Critical process parameters, Operating range, Robustness

(c) 2021 The Authors. Published by Innovare Academic Sciences Pvt Ltd. This is an open access article under the CC BY license (https://creativecommons.org/licenses/by/4.0/)

DOI: https://dx.doi.org/10.22159/ijcpr.2021v13i2.41548. Journal homepage: https://innovareacademics.in/journals/index.php/ijcpr

\section{INTRODUCTION}

The main objective of any pharmaceutical plant is to manufacture products of required attributes and quality consistently at the lowest possible cost. Quality comes through designing and proper controls of manufacturing parameters [1]. Repeat testing and resampling will not improve the quality. Process validation ensure the process is suitable and under control [2]. The process validation is done to check whether the formula is robust or not, to check for batch-to-batch reproducibility and to find out whether the process is under control or not [3]. A validated processes is necessary for attaining cGMP in a pharmaceutical unit that manufactures products using common equipment, also for regulatory and compliance requirement and to avoid the possibility of rejected or recalled batches $[4,5]$. Thereby each step must be controlled to maximize the probability that finished products meets all specifications. Hence, there is need to study process validation during manufacturing to assure the quality of products [6]. Process validation for tablet will be carried out by monitoring the critical parameters of the process while taking production runs, sampling and testing at different process steps to provide the efficiency of the process [7]. Process validation is performed to validate the process parameter of tablet and is generally followed as per the standard operating procedure for manufacturing process used in the manufacturing facility of the company consistently and concurrently to yield the results not exceeding predetermined limit residues through established methods which are employed in manufacturing facility $[8,9]$.

\section{Process validation-general principles and practices}

Process validation is essentially the accumulating and evaluating information, from the process design stage to the industrial production that provides scientific proof that any process is capable of delivering quality product continuously [10]. Process validation include a series of activities taking place over the lifecycle of the product and process. This guidance explains process validation activities in three stages [11].

Stage1-Process Design: During this stage, manufacturing process is explained based on information gained through development and scale-up activities.

Stage2-Process Qualification: During this stage, stage 1 is evaluated to determine if the process is capable of reproducible commercial manufacturing.

Stage3-Continued Process Verification: Ongoing assurity is gained during regular production that the process is in a position of control $[12,13]$.

A successful validation program relies upon information and facts from product and process development. This knowledge and understanding is the basis for setting up an approach for control of the manufacturing process that gives products with the desired quality attributes [14]. The critical parameters in the process were recognized, which may affect the quality of the final product $[15,16]$. The aim of the present work is process development, optimization and validation, taking into consideration of all above three stages.

\section{MATERIALS AND METHODS}

There was the change of the manufacturing site prior to scale up. Small batches were manufacture in old block and pre-process batch manufacture in new block with increased batch size. The tablet properties were compared from two sites. The company was adequately equipped with the necessary set-up and the allied requirements. The raw material (API and excipient) which were used, taken from an approved vendor source. The equipment which was used at various stages of manufacturing was already been 
qualified and validated as per the respective validation master plan and other standard operating procedures. Machine was set within its operating range. The compaction parameter is given in table 1 .

Table 1: Compaction parameter

\begin{tabular}{lll}
\hline S. No. & Parameter & Set value \\
\hline 1 & Blender speed & $15 \mathrm{rpm}$ \\
2 & Blending time & $5-10 \mathrm{~min}$ \\
3 & Machine Speed & $15-40 \mathrm{rpm}$ \\
4 & Compression Force & $8-35 \mathrm{KN}$ \\
\hline
\end{tabular}

Uncoated tablets of Allopurinol was prepared in which the amount of active ingredient was $300 \mathrm{mg}$ and total weight of the tablet 540 mg. The granulated material was dried in FBD (Alliance, India) followed by milling (Saan, India). The milled granules were lubricated for a specified time interval in a blender (Saan, India). Using BB-type punch tooling, compression was performed in a compression machine (Sejong, Korea). Different batches were evaluated for hardness, weight variation, thickness and friability. Weight variation test had performed by taking 10 tablets using an electric balance (Sartorius). A dial caliper (Mitutoyo) used to measure the thickness of tablet. Tablet hardness measured using a hardness tester (Dr. Schleuniger Pharmtron). Disintegration studies were performed using Electrolab ED-2L at $37+0.2{ }^{\circ} \mathrm{C}$. The time required to disintegrate the tablet was noted [17]
Friability of the tablets was determined by testing tablets with a weight corresponding to $6.5 \mathrm{~g}$ in Electrolab EF-1W for 4 minute with set count 100. As the uniformity of dosage units can be demonstrated by either of two methods, Content Uniformity or Weight Variation. Here, the test for weight variation is applicable for uncoated tablets containing $25 \mathrm{mg}$ or more of a drug substance comprising $25 \%$ or more, by weight, of the dosage unit. Dissolution studies were performed using USP, Paddle type II method (Labindia, DISS 2000)at $37+0.5^{\circ} \mathrm{C}$ and $75 \mathrm{rpm}$ using $0.01 \mathrm{~N} \mathrm{HCl}$ with $900 \mathrm{ml}$ dissolution media. A $10 \mathrm{ml}$ aliquot of sample was withdrawn at a regular time interval, filtered and same amount replaced to maintain sink condition. In $100 \mathrm{ml}$ volumetric flask, $3 \mathrm{ml}$ of filtrate was taken and were diluted with dissolution media. The sample solution was analyzed at $250 \mathrm{~nm}$ by UV spectrophotometer (perkin Elmer $\lambda-25$ ). The cumulative \% drug release was calculated [17]

\section{Sample withdrawn at different interval}

During compression 100 tablets from each stage, beginning, middle, end collected at frequency of atleast once in 30 minutes. At different hardness $(8,13,18 \mathrm{SCU}) 100$ tablets were collected for analysis. After compression 150 tablets were withdrawn.

\section{RESULTS AND DISCUSSION}

The machine speed was fixed and compression force were evaluated for pre-process batch in new block. Machine speed 15-40 rpm and compression forces ranging from 8-35 $\mathrm{KN}$ has been established and the hardness variation outcome was observed as given in table 2 .

Table 2: Hardness variation in pre-process batch with increase batch size at new block

\begin{tabular}{|c|c|c|c|c|c|c|}
\hline Batch & Parameters & Std as per BMR & Beggining & Middle & End & Composite \\
\hline $\begin{array}{l}\text { Small } \\
\text { batch }\end{array}$ & Hardness (SCU) & $\begin{array}{l}8.00-13.00 \mathrm{SCU} \\
10.50+2.50 \mathrm{SCU}\end{array}$ & $9.00-11.40$ & $9.40-11.30$ & $8.80-12.00$ & $8.20-12.30$ \\
\hline $\begin{array}{l}\text { Pre process } \\
\text { batch }\end{array}$ & Hardness (SCU) & $\begin{array}{l}8.00-13.00 \mathrm{SCU} \# \\
10.50+2.50 \mathrm{SCU}\end{array}$ & $14.6-15.8$ & $13-15.4$ & $14.7-17.8$ & $5.4-19.5 \#$ \\
\hline
\end{tabular}

\#High hardness sample was observed at 18 SCU

Different tablet properties were compared and found to be within specification. Machine was set within its operating range. Pre-process batch was manufactured at upper and lower processing limits. The hardness data obtained at extremes is as mentioned in table 3.

Table 3: Observation at extremes of hardness for pre-process batch

\begin{tabular}{|c|c|c|c|c|c|c|c|c|}
\hline Batch & Parameter & Std as per BMR & $\begin{array}{l}\text { Hardness } \\
8 \text { SCU } \\
\text { (15RPM) }\end{array}$ & $\begin{array}{l}\text { Hardness } \\
8 \text { SCU } \\
\text { (35RPM) }\end{array}$ & $\begin{array}{l}\text { Hardness } \\
18 \mathrm{SCU} \\
(15 \mathrm{RPM})\end{array}$ & $\begin{array}{l}\text { Hardness } \\
18 \mathrm{SCU} \\
\text { (35RPM) }\end{array}$ & $\begin{array}{l}\text { Hardness } \\
13 \text { SCU } \\
(15 R P M)\end{array}$ & $\begin{array}{l}\text { Hardness } \\
13 \text { SCU } \\
\text { (35RPM) }\end{array}$ \\
\hline $\begin{array}{l}\text { Pre process } \\
\text { batch }\end{array}$ & $\begin{array}{l}\text { Hardness } \\
\text { (SCU) }\end{array}$ & $\begin{array}{l}8.00-13.00 \mathrm{SCU} \\
10.50+2.50 \mathrm{SCU}\end{array}$ & $9.1-12.4$ & $11.3-16.2$ & $14.9-16.5$ & $11.2-16.4$ & $11.8-14.0$ & $11.5-15.2$ \\
\hline
\end{tabular}

Only those parameters that recognized as critical are then optimized during manufacture. The compression parameter that are modified are machine speed and compression force. Based on collected data machine speed and compression force have been established as 15-35 rpm and 8-25 KN. After approved changes it is observed that the result of pre-processing validation batches at different manufacturing stagesi. e. mixing, granulation, drying, lubrication, compression are found satisfactory and resulted in acceptable tablet properties.
The critical process parameter and critical process steps which were identified at various stages of manufacturing are found within specification limits. Thus the process which is optimized is considered as validated. Hence it can be recommended that; same parameters shall be considered as final for further production of batches of allopurinol USP $300 \mathrm{mg}$ tablet.

Quality control analysis of three batches was evaluated for different test parameters. The results are compiled in table 4 .

Table 4: Analysis of different test parameter

\begin{tabular}{llc}
\hline Test parameter & Specification & Observation of individual result \\
\hline weight variation & $513-567 \mathrm{mg}$ & $520-562 \mathrm{mg}$ \\
Thickness & $4.90-5.30 \mathrm{~mm}$ & $5.12-5.28 \mathrm{~mm}$ \\
Hardness & $8-18 \mathrm{SCU}$ & $8.7-17.7 \mathrm{SCU}$ \\
Disintegration & NMT $10 \mathrm{~min}$ & Meets the requirement \\
Friability & NMT $1.0 \%$ & Meets the requirement \\
Uniformity of dosage & RSD NMT 6.0\% & RSD of all individual result are<6\% \\
Dissolution & NLT $75 \%(Q)$ of the labeled amount of Allopurinol is dissolved in 45 min. & Meets the requirement \\
Assay & $291-309 \mathrm{mg}$ & $298.77-304.80 \mathrm{mg}$ \\
\hline
\end{tabular}




\section{CONCLUSION}

On the basis of an evaluation of results, a conclusion is drawn to state that process was optimized and gave a reproducible product that meets predetermined quality requirements and do so consistently and reliably.

The Pre-Process validation data for one batch of Allopurinol Tablets USP, $300 \mathrm{mg}$ manufactured in new block was reviewed and was found satisfactory. As per the review of one Pre-Process validation batch data, it is recommended to proceed for manufacturing three process validation batches with a change in site and increased batch size. The validation batches will be manufactured with updated BMR by incorporating recommended changes.

Three consecutive batches of Allopurinol Tablets USP, $300 \mathrm{mg}$ manufactured in new block were reviewed. The process and analytical results comply with the product specification. The study demonstrates conformance with the validation protocol and the predetermined acceptance criteria. Hence, process for manufacturing of Allopurinol Tablets USP, $300 \mathrm{mg}$ is validated.

\section{ACKNOWLEDGEMENT}

I am grateful to Dr. P. K. Dubey (Principle, SVCP Indore) for providing me the opportunity to do the wonderful project. I am highly thankful to Dr. Nimita Manocha for all the support in completion of this work.

\section{FUNDING}

$\mathrm{Nil}$

\section{AUTHORS CONTRIBUTIONS}

All the authors have contributed equally.

\section{CONFLICT OF INTERESTS}

The authors declare that they have no conflict of interest.

\section{REFERENCES}

1. Leon Lachman, Herbert A Liberman, Joseph L Kaing, Joseph L Kaing. The theory and practice of Industrial pharmacy, Varghese Publishing House. $3^{\text {rd }}$ edition.; 1986. p. 293-336.

2. Garston Smith H. Considerations for improving validation. J Validation Technol 2001;7:150-7.
3. Nash Robert A, Wacher Alfred H. Pharmaceutical process validation an International. 3rd edition. New York; 2003. p. $159,198-229$

4. USA FDA, Drug process validation and drug application, Singapore; 2001.

5. http://www.fda.gov/Drugs/DevelopmentApprovalProcess/Ma nufacturing/QuestionsandAnswersonCurrentGoodManufacturi ngPracticescGMPforDrugs/ucm071836.htm. [Last accessed on 02 Oct 2020]

6. Raghunandanan R. Validation aspects of solid dosage forms pharma times; 2009. p. 41.

7. Guidelines on General Principles of Process Validation, Division of Manufacturing and Product Quality, CDER, FDA, Rockville, Maryland; 1987.

8. Guidance for Industry SUPAC-IR/MR: Immediate Release and Modified Release Solid Oral Dosage Forms U. S. Department of Health and Human Services Food and Drug Administration Center for Drug Evaluation and Research (CDER); 1999.

9. Shah Dhiron. Bureau of the census. Census of manufactures. U. S. Department of Commerce. 1995. SUPAC-IR and XPACs Industry Survey Report; 1997.

10. Quality Management Systems-Process Validation. edition 2. Available from: http://www.ghtf.org/sg3/sg3-final.html) [Last accessed on 02 Oct 2020

11. Guidance for Industry, Scale-Up and Postapproval Changes, CDER, FDA; 1995.

12. http://www.fda.gov/Drugs/GuidanceComplianceRegulatoryInfo rmation/Guidances/default.htm [Last accessed on 02 Oct 2020]

13. Melkebeke VB, Vervaet C, Remon JP. Validation of a continuous granulation process using a twin-screw extruder. Int J Pharma 2008;356:224-30.

14. Jatto E, Okhamafe AO. An overview of pharmaceutical validation and process controls in drug development. Trop J Pharm Res 2002;1:115-22.

15. ICH harmonised tripartite guideline, "GMP guide for active pharmaceutical ingredients" Q8, current step 4 version, 10 Nov 2000.

16. Williams AC, Cooper VB, Thomasb L. ICH harmonised tripartite guideline, "GMP guide for active pharmaceutical ingredients" Q8, current step 4 version, 10 Nov 2000. Evaluation of physical drug form during granulation, tabletting and storage. Int Pharm 2004;275:29-39.

17. United States pharmacopeia NF; 2011. 